\title{
Effect of cycloheximide upon maturation of bovine oocytes
}

\author{
M. Šimon, F. Jilek and J. Fulka Jr * \\ Institute of Animal Production, 10400 Prague 10, Uhřinèves, Czechoslovakia
}

(3rd Franco-Czechoslovak Meeting, INRA, Jouy-en-Josas, 13-14 December 1988)

Summary - Germinal vesicle breakdown (GVBD) of bovine oocytes was completely blocked by cycloheximide added to culture medium at concentrations of $1-20 \mu \mathrm{g} / \mathrm{ml}$. Nevertheless, under such conditions a certain degree of chromatin condensation inside the germinal vesicle was observed. The inhibitory effect was not influenced by the presence or absence of cumulus cells and was fully reversible; but the process of GVBD was then significantly accelerated. The critical period in which the proteins necessary for GVBD are synthesized lasts approximately the first $5 \mathrm{~h}$ of culture. When germinal vesicle-arrested oocytes are fused to maturing bovine oocytes containing condensed chromosomes, GVBD of immature oocytes occurs within $3 \mathrm{~h}$, even in the presence of cycloheximide. In the mouse, GVBD cannot be inhibited by protein synthesis inhibitors. When immature mouse oocytes are fused with immature bovine oocytes and the giant cells are then cultured in cycloheximidesupplemented medium, both GVs are observed, or only mouse GVBD occurs in common cytoplasm after $8 \mathrm{~h}$ of culture. We conclude that protein synthesis is necessary for GVBD of bovine oocytes. Our results also suggest that maturation-promoting factor (MPF) is not autocatalytically amplified in mammalian oocytes.

oocyte - maturation - cycloheximide - bovine

Résumé - Effet de la cycloheximide sur la maturation des ovocytes bovins. La rupture de la vesicule germinative (RVG) d'ovocytes bovins est complètement inhibée par la cycloheximide ajoutée au milieu de culture, à la concentration de 1 à $20 \mu \mathrm{g} / \mathrm{ml}$. Cependant dans ces conditions un certain degré de condensation de la chromatine est observé dans la vésicule germinative. L'effet inhibiteur, non modifié par la présence ou l'absence de cellules du cumulus, est complètement réversible; en cas de réversion, la processus de RVG est significativement accéléré. La période critique pendant laquelle les protéines nécessaires pour la RVG sont synthétisées dure environ les 5 premières $h$ de culture. Lorsque des ovocytes bloqués au stade de la vésicule germinative sont fusionnés à des ovocytes bovins en cours de maturation contenant des chromosomes condensés, la RVG des ovocytes immatures se produit dans les 3 h, même en présence de cycloheximide. Chez la souris, la RVG ne peut être empêchée par des inhibiteurs de synthèse protéique. Quand des ovocytes murins immatures sont fusionnés avec des ovocytes bovins immatures et que les cellules géantes sont cultivées dans un milieu contenant de la cycloheximide, les 2 vésicules germinatives persistent dans le cytoplasme commun ou seulement celle d'origine bovine, après $8 \mathrm{~h}$ de culture. La synthèse de protéines apparaît donc nécessaire pour la RVG des ovocytes bovins. Nos résultats suggèrent aussi que le facteur promouvant la maturation (MFP) n'est pas amplifié de manière autocatalytique dans les ovocytes de Mammifères.

ovocyte - maturation - cycloheximide - bovin

* Correspondence and reprints. 


\section{INTRODUCTION}

Until recently it has been generally accepted that protein synthesis is not necessary for the initiation of mammalian oocyte maturation. This assumption was based on observations in the mouse where germinal vesicle breakdown occurs in the presence of protein synthesis inhibitors (Schultz \& Wassarman, 1977; Masui \& Clarke, 1979). In the rat, GVBD occurs in the presence of cycloheximide; however, when these oocytes are cultured in dbcAMP and cycloheximide-supplemented medium and thereafter in only cycloheximide-supplemented medium, the process of GVBD is significantly reduced (Ekholm \& Magnusson, 1979). These results indicate the existence of short-lived proteins necessary for meiosis resumption. On the other hand, maturation of porcine and ovine oocytes is completely blocked by protein synthesis inhibitors (Fulka Jr. et al., 1986; Moor \& Crosby, 1986). The fusion of pig oocytes in metaphase I to oocytes with an intact germinal vesicle revealed that cycloheximide did not inhibit GVBD induced by maturing ooplasm (Fulka Jr. et al., 1986). Those results demonstrate the existence of species-specific differences. It has recently been published that bovine oocyte maturation is also effectively blocked by cycloheximide (Hunter \& Moor, 1987; Sirard et al., 1988). Our paper provides some supplementary information concerning the effect of cycloheximide on bovine oocyte maturation and the induction of the GVBD after intra- and/or interspeciesspecific (mouse/bovine) fusion.

\section{MATERIALS AND METHODS}

Bovine oocytes were aspirated from $2-5 \mathrm{~mm}$ diameter follicles of ovaries from slaughtered ani- mals; only those occytes surrounded by compact cumulus oophorus were used. Oocytes were then cultured in $0.1 \mathrm{ml}$ culture medium (TC 199) as droplets under paraffin oil at $37.5^{\circ} \mathrm{C}$ under $5 \% \mathrm{CO}_{2}$ in air, according to the experimental procedure (see Results). The composition of the medium was the same as described previously (Fulka Jr. et al., 1986). The medium was supplemented by cycloheximide (Serva, Heidelberg, FRG) at concentrations of $1,5,10$ or $20 \mu \mathrm{g} / \mathrm{ml}$. When cumulus-free oocytes were used, their cumuli were removed mechanically by pipetting. For fusion, cumulus-free oocytes were incubated in pronase $(0.1 \%)$ to remove zonae pellucidae.

Mouse oocytes were isolated from large antral follicles of females (A/Ph) strain taken $48 \mathrm{~h}$ apart with 5 IU of PMSG. Manipulation of these oocytes was performed in medium containing $100 \mu \mathrm{g} / \mathrm{ml}$ of dbcAMP (Serva, Heidelberg, FRG) to prevent GVBD (Cho et al., 1974). Cumulus cells were removed mechanically and zonae pellucidae were dissolved in pronase $(0.5 \%)$. Before fusion, the cells chosen for specific combination (see Results) were agglutinated in phytohemagglutinin $(200 \mu \mathrm{g} / \mathrm{ml}$ in PBS; Serva, Heidelberg, FRG) and briefly washed in isotonic glucose solution. They were then transferred in the same solution to the chamber (electrode distance $200 \mu \mathrm{m}$ ) of an electrofusion apparatus (CFA 400; Krüss, Hamburg, FRG) and exposed to the following fusion conditions : cell orientation in a.c. (alternating current) field $(3 \mathrm{~V}, 600$ $\mathrm{kHz}$ for $5-10 \mathrm{~s}$ ), followed by 2 fusion pulses of $15 \mathrm{~V}$ d.c. (direct current), each lasting $30 \mu \mathrm{s}$, at $0.1-s$ intervals. After the fusion pulses, the a.c. voltage was reduced from $3 \mathrm{~V}$ to 0 over a period of $30 \mathrm{~s}$. The cells were then washed in cycloheximide-supplemented medium and cultured in the latter for defined time intervals (see Results).

At the end of each culture-interval, oocytes without cumulus as well as fused cells were mounted on slides, fixed in acetic-alcohol $(1: 3$, $v / v)$, stained in orcein $(1 \%)$ and examined under a phase-contrast microscope.

\section{RESULTS}

The present results clearly show that maturation of bovine oocytes is effectively 
blocked by cycloheximide. Whereas in cycloheximide-free medium GVBD occurred in nearly all oocytes $(93.5 \%$ ), cycloheximide-supplemented medium blocked this process completely, even at a very low concentrations of inhibitor (Table I). The inhibition of GVBD was observed even in the absence of cumulus (GV-93\%, 28/30) in the medium containing $10 \mu \mathrm{g} / \mathrm{ml}$ cycloheximide. The same inhibitor concentration was used in further experiments. The inhibitory effect was fully reversible. When the intact oocytes were cultured for $24 \mathrm{~h}$ in cycloheximide-supplemented medium, then washed several times in cycloheximide-free medium and cultured in it for 24 $h$, GVBD occurred in $98 \%$ of these oocytes (50/51).

However, when the oocytes were blocked for $24 \mathrm{~h}$ by cycloheximide a certain degree of chromatin condensation occurred inside the GV. This indicated that some maturation processes were not blocked and/or were protein synthesis independent. We compared the rapidity of GVBD between the oocytes precultured for $24 \mathrm{~h}$ in cycloheximide with the oocytes freshly isolated from follicles. Both types of oocytes were cultured in cycloheximide- free medium for $4 \mathrm{~h}$. After this culture interval, GVBD in freshly isolated oocytes was observed in only $28.4 \%(23 / 81)$, whereas in precultured oocytes $(24 \mathrm{~h})$, condensed chromosomes were present in $75.9 \%$ (44/ 58 ); in the latter group GVBD was significantly accelerated.

It would be interesting to determine the sensitive period in which it is possible to block GVBD. The results are presented in Table II. The oocytes were incubated in cycloheximide-free medium for different timeintervals and then cultured in cycloheximide-supplemented medium for up to $12 \mathrm{~h}$ from the start of the experiment. The sensitive period lasted $\approx 4-5 \mathrm{~h}$ (Table II). GVBD occurred in most cells when oocytes were precultured in normal medium for $6 \mathrm{~h}$. In control oocytes fixed 1-2, 4, 5 and $6 \mathrm{~h}$ after the onset of culture, GVs were present in $91.3 \%$ (42/46), 81.0\% (17/ $21), 80.8 \%(42 / 52)$ and $46.4 \%(26 / 56)$ respectively.

Fulka Jr. et al. (1986) demonstrated that it is possible to induce GVBD of the arrested oocytes by fusion with the oocytes containing condensed chromosomes. In the present experiment the cycloheximidearrested oocytes were fused with bovine

Table I. Effect of cycloheximide upon germinal vesicle breakdown of bovine oocytes*.

\begin{tabular}{ccccc}
\hline \multirow{2}{*}{$\begin{array}{c}\text { Cycloheximide } \\
\text { Concentration } \\
(\mu \mathrm{g} / \mathrm{m} /)\end{array}$} & $\begin{array}{c}\text { No. of } \\
\text { oocytes }\end{array}$ & \multicolumn{3}{c}{ Stage of maturation } \\
\cline { 2 - 5 } & & GV (\%) & GVBD (\%) & degenerated (\%) \\
\hline 0 & 93 & $2(2.2)$ & $87(93,5)$ & $4(4.3)$ \\
1 & 73 & $71(97.3)$ & - & $2(2.7)$ \\
5 & 66 & $65(98.5)$ & - & $1(1.5)$ \\
10 & 36 & $34(94.4)$ & - & - \\
20 & 33 & $33(100)$ & & - \\
\hline
\end{tabular}

\footnotetext{
* Oocytes were cultured for $24 \mathrm{~h}$.

GV $=$ germinal vesicle.

GVBD = germinal vesicle breakdown.
} 
Table II. Effects of oocyte preincubation on cycloheximide block of nuclear maturation.

\begin{tabular}{|c|c|c|c|c|c|}
\hline \multicolumn{2}{|c|}{ Time of culture $(h)$} & \multirow{2}{*}{$\begin{array}{c}\text { No. of } \\
\text { oocytes }\end{array}$} & \multicolumn{3}{|c|}{ Stage of maturation } \\
\hline $\begin{array}{l}\text { control } \\
\text { medium }\end{array}$ & $\begin{array}{l}\text { medium with } \\
\text { cycloheximide }\end{array}$ & & $G V(\%)$ & GVBD (\%) & degenerated (\%) \\
\hline $1-2$ & $10-9$ & 29 & $27(93.1)^{a}$ & $2 \quad(6.9)$ & - \\
\hline 4 & 7 & 27 & $19(70.4)^{b}$ & $8(29.6)$ & - \\
\hline 5 & 6 & 45 & $17(37.8)^{c}$ & $27(60.0)$ & $1(2.2)$ \\
\hline 6 & 5 & 52 & $7(13.5)^{d}$ & $44(84.6)$ & $1(1.9)$ \\
\hline 11 & 0 & 54 & $2(3.7)^{d}$ & $51(94.4)$ & $1(1.9)$ \\
\hline
\end{tabular}

a, b, c, d Numbers with different superscripts are significantly different $\left(\chi^{2}, P<0.01\right)$.

oocytes precultured for 8-9 h. In these oocytes, GVBD occured in nearly $75 \%$ of oocytes. The fused cells were fixed $3 \mathrm{~h}$ post-fusion after culture in cycloheximidesupplemented medium. The giant cells with 2 GVs were discarded (20\%), as in these cases 2 immature oocytes were fused. The results are presented in Table III, and clearly indicate that the cytoplasm originating from maturing oocytes induced breakdown of the GV from cycloheximidearrested oocytes. In the cytoplasm of fused cells, 2 groups of condensed chromatin were observed. To assess the effect of maturation-promoting factor (MPF) which is responsible for GVBD, interspecif- ic fusion between mouse (GV) and bovine (GV) oocytes was performed. It was of interesting to determine if the cytoplasm of mouse oocytes, which induces GVBD even in the presence of cycloheximide in intact oocytes, was able to induce GVBD of cycloheximide-sensitive bovine oocyte. The fused oocytes were incubated for $8 \mathrm{~h}$ in cycloheximide-supplemented medium. The fusion occurred in $\approx 50 \%$ of treated cells. Although in unfused mouse oocytes GVBD occured in nearly all cases, in interspecific giant cells the induction of GVBD was only rarely observed. In most cases, 2 GVs were present in common cytoplasm (Fig. 1). In somes cells only mouse GVBD

Table III. Culture of fused bovine and mouse oocytes in medium with cycloheximide.

\begin{tabular}{|c|c|c|c|c|}
\hline \multirow{2}{*}{$\begin{array}{l}\text { Type of } \\
\text { fusion }\end{array}$} & \multirow{2}{*}{$\begin{array}{l}\text { Stage of } \\
\text { maturation before } \\
\text { fusion }\end{array}$} & \multicolumn{3}{|c|}{ Stage of maturation post-fusion } \\
\hline & & $G V+G V$ & 2 groups of chromosomes & GV + chromosome group \\
\hline$B \times B$ & $G V \times L D$ & - & 16 & 1 \\
\hline$B \times M$ & $\mathrm{GV} \times \mathrm{GV}$ & 22 & 5 & 4 \\
\hline
\end{tabular}

$B=$ bovine $; M=$ mouse $; G V=$ germinal vesicle $; D=$ late diakinesis . 
occurred, whereas bovine GV remained intact (Fig. 2). In unfused bovine oocytes GVs were present in all cases. Few (16) fused (bovine-GV $x$ mouse-GV) cells were cultured in cycloheximide-free medium for the same time interval. In these fusion products, one common group of chromosomes was observed in the cytoplasm (Fig. 3). When comparing the morphology of these chromosomes with the chromosomes in fused (bovine-GV $\times$ bovine-LD, M) oocytes cultured with cycloheximide, a distinct difference was evident. In the former case one group of chromosomes exhibited perfect morphology, whereas in the presence of cycloheximide, clumps of condensed chromatin were usually present. In mouse-bovine oocyte hybrid cells cultured in the presence of cycloheximide, in which both GVs were broken down, 2 clumps of chromatin were also present. These results indicate that cycloheximide not only inhibits GVBD of bovine oocyte maturation, but that the morphology of a group of chromosomes and their movement in the cytoplasm is also affected.

\section{DISCUSSION}

Our results confirm and extend the results published by Hunter \& Moor (1987) and Sirard et al. (1988), showing the high sensitivity of bovine oocytes to cycloheximide. This means that cattle oocytes belong to the group of mammals in which GVBD is protein synthesis-dependent (pig; Fulka Jr. et al., 1986; sheep : Moor \& Crosby, 1986). As has been shown in the rat GVBD inhibition is possible only after previous preincubation of these oocytes in dbcAMP + cycloheximide-supplemented medium and subsequent culture in the presence of protein synthesis inhibitor (Ekholm \& Magnusson, 1979). However, we were unable to demonstrate the same effect with mouse oocytes under the same culture conditions (Fulka Jr., unpublished results). It is clear that the mouse is the only mammalian species of all those species studied so far shown to be independent of protein synthesis for GVBD. Addition of cycloheximide to the bovine oocytes after preincubation in drug-free medium has revealed the sensitive period in which it is possible to block GVBD. This period lasts $\approx 5 \mathrm{~h}$. Although the GVBD process is not synchronous (see Motlik et al., 1978), these results confirm the observations of Moor \& Crosby (1986) in sheep. These authors claimed that protein synthesis is necessary for up to $1-2 \mathrm{~h}$ preceding GVBD.

Interestingly, even if nuclear membrane breakdown is inhibited by the drug, a certain degree of chromosome condensation is observed in karyoplasm. This may indicate that the whole process of GVBD represents several steps, some of them probably being protein synthesis-independent, i.e. chromosome condensation. Removal of the oocytes from cycloheximidesupplemented medium resulted in accelerated germinal vesicle breakdown; this phenomenon was first described by Osborn \& Moor (1983) in sheep and later in pig (Kubelka et al., 1988).

It has recently been described that disassembly of the somatic cell nucleus represents at least 3 independent processes (Newport and Spann, 1987). It is possible that a similar situation also exists in mammalian oocytes. It remains to be determined which of them is protein synthesisdependent. Introduction of maturationpromoting factor (MPF) induces GVBD of the arrested oocytes in all species studied so far, even in the presence of cycloheximide (Masui \& Clarke, 1979). This is in 

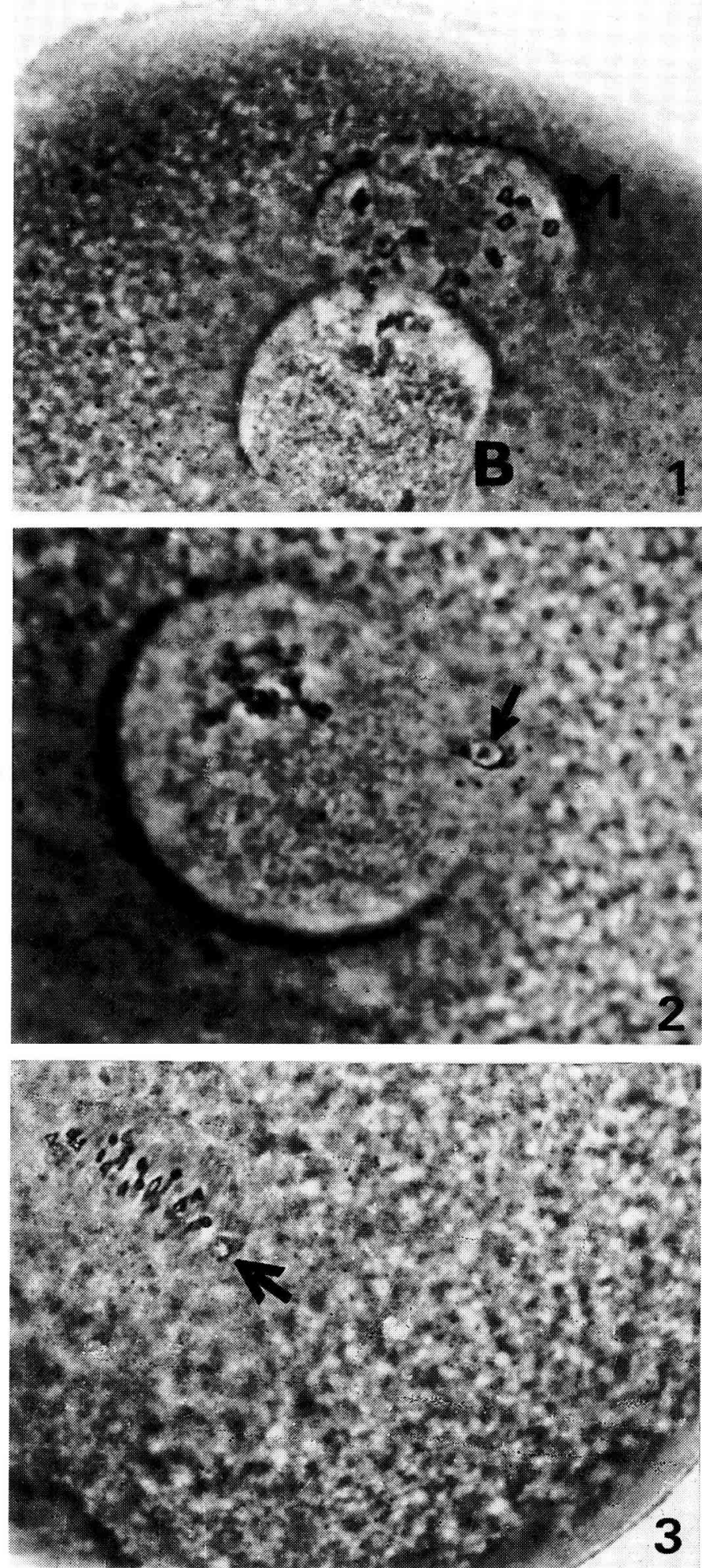
agreement with our previous results in the pig (Fulka Jr. et al., 1986). However, the morphology of condensed chromosomes differs from those present in fused cells cultured in cycloheximide-free medium. The influence of protein synthesis-inhibitor upon chromosome morphology was firstly described by Clarke \& Masui (1983) in mouse and later by Fulka Jr. et al. (1986) and Sirard et al. (1988) in cattle. From these studies it is clear that there are some sensitive stages during which chromosome behavior is influenced. In our experiments the presence of the drug resulted in chromosome clumping. The movement of chromosomes in common cytoplasm was also affected. An interesting situation was observed after fusion of mouse (GV) oocyte to bovine (GV) oocyte and the culture of this giant cell in cycloheximide-supplemented medium. As mentioned above, the mouse oocyte cytoplasm is drug-independent and induces a GVBD of its own. However, our results demonstrate that in fused cell cytoplasm, both GVs remained well conserved and in some cases only mouse GVBD occurred. This may indicate that production of MPF by mouse cytoplasm is blocked; or what is more probable, that some MPF is produced but that it is extensively diluted in the common cytoplasm. The amount of MPF is thus insufficient to induce GVBD. These results also confirm our results that MPF is not autocatalytically amplified in mammalian oocytes (Fulka Jr. et al., 1988), whereas in amphibian and starfish oocyte, a minute amount of maturing cytoplasm will induce GVBD of an immature oocyte even in the presence of cycloheximide (Masui \& Clarke, 1979).

\section{REFERENCES}

Cho W.K., Stern S. \& Biggers J.D. (1974) Inhibitory effect of dibutyryl cAMP on mouse oocyte maturation in vitro. J. Exp. Zool. 187, 383-386

Clarke H.J. \& Masui Y. (1983) The induction of reversible and irreversible chromosome decondensation by protein synthesis inhibition during meiotic maturation of mouse oocyte. Dev. Biol. 97, 291-301

Ekholm C. \& Magnusson C. (1979) Rat oocyte maturation : effects of protein synthesis inhibitors. Biol. Reprod. 21, 1287-1293

Fulka J. Jr., Fléchon J.E., Motlík J. \& Fulka J. (1988) Does autocatalytic amplification of maturation-promoting factor (MPF) exist in mammalian oocytes ? Gamete Res. 21, 185-192

Fulka J. Jr., Motlík J., Fulka J. \& Jílek F. (1986) Effect of cycloheximide on nuclear maturation of pig and mouse oocytes. J. Reprod. Fertil. 77, 281-285

Hunter A.G. \& Moor R.M. (1987) Stagedependent effects of inhibiting ribonucleic acids and protein synthesis on meiotic maturation of bovine oocytes in vitro. J. Dairy Sci. 70, 16461651

Kubelka M., Motlík J., Fulka J. Jr., Procházka R., Rimkevičová Z. \& Fulka J. (1988) Time sequence of germinal vesicle breakdown in pig oocytes after cycloheximide and p-aminobenzamine block. Gamete Res. 19, 423-431

Masui Y. \& Clarke H.J. (1979) Oocyte maturation. Int. Rev. Cytol. 57, 185-282

Fig. 1. Giant cell developed after fusion of immature bovine and mouse oocyte and cultured for $8 \mathrm{~h}$ in cycloheximide-supplemented medium. Both GVs are well conserved (M, mouse; B, bovine). $(\times 500)$.

Fig. 2. Giant cell developed after fusion of immature bovine and mouse oocyte and cultured for $8 \mathrm{~h}$ in medium with cycloheximide. Here only mouse GV broke down (arrow). Bovine GV was well conserved (x 500).

Fig. 3. This hybrid cell (mouse GV $x$ bovine GV) was cultured for $8 \mathrm{~h}$ in cycloheximide-free medium. Both GVs broke down and one common group of chromosomes was formed. (x 600). 
Moor R.M. \& Crosby I.M. (1986) Protein requirements for germinal vesicle breakdown in ovine oocytes. J. Embryol. Exp. Morphol. 94, 207-220 Motlík J., Koefoed-Johnsen H.H. \& Fulka J. (1978) Break-down of the germinal vesicle in bovine oocytes cultivated in vitro. J. Exp. Zool. 205, 377-384

Newport J. \& Spann T. (1987) Disassembly of the nucleus in mitotic extracts; membrane vesicularization, lamin disassembly, and chromosome condensation are independent processes. Cell 48, 219-230
Osborn J.C. \& Moor R.M. (1983) Time dependent effects of $\alpha$-amanitin on nuclear maturation and protein synthesis in mammalian oocytes. $J$. Embryol. Exp. Morphol. 73, 317-338

Schultz R.H. \& Wassarman P.M. (1977) Biochemical studies of mammalian oogenesis : protein synthesis during oocyte growth and meiotic maturation in the mouse. J. Cell Sci. 24, 167197

Sirard M.A., Florman H., Barnes F. \& First N.L. (1988) In vitro maturation of bovine oocytes : nuclear changes and protein requirement. Theriogeneology 29, 307 